\title{
Multifunctionality at what scale? A landscape multifunctionality assessment for the European Union under conditions of land use change
}

\author{
Julia Stürck • Peter H. Verburg
}

Received: 2 June 2016/Accepted: 31 October 2016/Published online: 12 November 2016

(C) The Author(s) 2016. This article is published with open access at Springerlink.com

\begin{abstract}
Context The provision of multiple ecosystem services (ES) within a landscape is commonly referred to as landscape multifunctionality. Modifying landscapes to increase multifunctionality and reduce trade-offs with concurrent services bears the potential to enhance sustainability in human-dominated landscapes. Assessing landscape multifunctionality is thus crucial for land management and planning, but lack of a clear definition and operationalization of multifunctionality impedes comparisons of different study results.

Objectives We want to address how elements of the study design affect results of multifunctionality assessments. Furthermore, we want to quantify future multifunctionality in the European Union (EU) and indicate the role of land use change and land use diversity on multifunctionality.

Methods We analyzed diverging scenarios depicting land use change in the EU between 2000 and 2040 for their effects on landscape multifunctionality. We tested different multifunctionality indicators at
\end{abstract}

Electronic supplementary material The online version of this article (doi:10.1007/s10980-016-0459-6) contains supplementary material, which is available to authorized users.

J. Stürck $(\bowtie) \cdot$ P. H. Verburg

Environmental Geography Group, VU University, De Boelelaan 1087, $1081 \mathrm{HV}$ Amsterdam, The Netherlands e-mail: julia.sturck@vu.nl various spatial scales based on the modelling of 12 ES and biodiversity indicators.

Results Particularly the analysis scale determines the interpretation of landscape multifunctionality. Coldspots identified by different indicators are in higher agreement than hotspots. We could not confirm links between land use diversity and landscape multifunctionality. While, at EU scale, multifunctionality slightly increases in future scenarios, agricultural intensification and (peri-)urban growth pose large threats to multifunctional landscapes.

Conclusions The choice of indicator and analysis scale strongly determine possible interpretations of the results. Rather than focusing on the impacts of land use change on multifunctionality, it is recommended to base land use policy on the impacts of locationspecific change on ES supply and demands.

Keywords Ecosystem services - Land use change Multifunctional $\cdot$ Spatial scale $\cdot$ Europe $\cdot$ Scenarios

\section{Introduction}

Landscapes provide diverse functions and services. Human-dominated landscapes, such as agricultural land and urban agglomerations, are often managed to serve a particular purpose. However, besides the intended purpose, multiple other services may be provided. The diversity and abundance of different 
landscape functions and services within the same landscape are commonly referred to as landscape multifunctionality. Multifunctional landscapes are often thought to be related to high levels of biodiversity (Otte et al. 2007; Pasari et al. 2013). Land use change may affect multifunctionality. Modifying a landscape to maximize the supply of a particular function often involves the depletion of other functions (Goldstein et al. 2012). These trade-offs are particularly strong between regulating services, such as water purification, and provisioning services, such as crop production (Bennett et al. 2009; RaudseppHearne et al. 2010; Howe et al. 2014). In case studies, it has been shown that appropriate land management decisions are able to counteract these trade-offs and facilitate multifunctional landscapes (Paletto et al. 2012; Bradford et al. 2014; Schindler et al. 2014). Modifying landscapes to increase their multifunctionality, therefore, bears the potential to enhance sustainability in human-dominated landscapes (Selman 2009; Waldhardt et al. 2010). Increasing multifunctionality is a proclaimed goal of landscape planning in many EU member states (Helming et al. 2008; van Zanten et al. 2014; Galler 2015). Assessment tools to quantify ecosystem services (ES) and to assess multifunctionality have become popular to determine current and future multifunctionality (Maes et al. 2012; Rodríguez-Loinaz et al. 2015).

The concept of landscape multifunctionality itself is not new (e.g., Beese 1996; Altieri 2000). Conceptual frameworks have been developed in time, and assessments at various scales have been published (e.g., Maes et al. 2012; Paletto et al. 2012; Plieninger et al. 2013b). Most recently, the analysis of time series and the effect of land use change on multifunctionality gained increasing attention (Elmhagen et al. 2015; Rodríguez-Loinaz et al. 2015).

Despite the concept of multifunctionality being elaborated over the last decade, there is still no clear definition as to what the key functions and services are that a particular landscape has to provide to be considered 'multifunctional'. Across the literature, there is no one single way to quantify multifunctionality. Often, the characterization and quantification of multifunctionality is based on metrics, such as diversity indicators that originate from biodiversity research and landscape ecology (Crouzat et al. 2015; Queiroz et al. 2015). The lack of a clear definition and operationalization of multifunctionality in ES assessments leads to problems in interpreting and comparing different studies.

The quantification of multifunctionality is dependent on the spatial scale of analysis. Multifunctionality can be found at the farm-, landscape or regional level (McGranahan 2014). Based on the research question, the chosen grain size of analysis influences the detected type of multifunctionality. For example, analyses on the grid-level (e.g. $1 \mathrm{~km}$ ) can elucidate the local multifunctionality, while regional analyses may illustrate benefits retrieved from interacting ecosystems (Mastrangelo et al. 2014). Yet, at the regional level, multifunctionality may as well be achieved by diverse monofunctional landscape units together. The scale-effects of multifunctionality are poorly covered in the literature (Mastrangelo et al. 2014). Many assessments are performed solely on arbitrarily chosen scales, such as municipalities or Nomenclature of Territorial Units for Statistics (NUTS) regions (Kienast et al. 2009; Queiroz et al. 2015), or at the level of ecosystem or spatial units (e.g., grid level, Burkhard et al. 2009). Assessments range from local assessments (often relying on field data) (Andersson et al. 2015) to continental assessments (primarily based on modeled data, e.g. Maes et al. 2014).

Most ES, and thus also multifunctionality, are susceptible to changes in land use and land use intensity (Dobson et al. 2006; Kremen et al. 2007; Metzger et al. 2008; Allan et al. 2015). In Europe, changes such as (peri-)urban growth, afforestation, abandonment of agricultural land, and changes in the land use intensity of agriculture profoundly changed European landscapes over the past decades (Fuchs et al. 2015; Gingrich et al. 2015). Particularly polarization of (rural) land use that consists of opposing trends of land abandonment at marginal locations in combination with intensification of land use at more suitable sites, potentially exerts strong impacts on multifunctional landscapes (Plieninger et al. 2013a).

We hypothesize that land use changes across Europe will affect multifunctionality in different ways and that the ongoing polarization of land use is leading to a decrease in multifunctionality, particularly at local levels.

The objective of this study is to analyze spatial and temporal patterns of multifunctionality in the European Union (EU) and to assess the impacts of land use change on multifunctionality. In analyzing the patterns 
of multifunctionality we test and compare various ways to quantify multifunctionality and analyze the effect of spatial scale on multifunctionality indicators. To analyze the effect of future land use change on multifunctionality we use a set of ES at the extent of the EU, available for the year 2000, and two diverging future scenarios for the year 2040. We discuss the findings in terms of the methodology and the ambitions of maintaining multi-functional land use.

\section{Materials and methods}

\section{Quantification of multifunctionality}

In the literature, many approaches to quantify multifunctionality are presented. Each of the presented indicators focusses on particular characteristics of multifunctionality. To quantify multifunctionality in our study, we selected four multifunctionality indicators that were recently presented and applied in the literature and that focus on different aspects of multifunctionality (Table 1): Number of ES that exceed particular thresholds $\left(\mathrm{T}_{30}-\mathrm{T}_{70}\right)$, the summed ES supply MESLI, Shannon's $H^{\prime}$ (SH), and Simpson's reciprocal index (SRI) (Raudsepp-Hearne et al. 2010; Pasari et al. 2013; Plieninger et al. 2013b; RodríguezLoinaz et al. 2015). In all multifunctionality calculations, we applied the same weight to all ES and biodiversity indicators. In the following section, the various approaches to quantify multifunctionality with a single indicator are presented in more detail.

A basic approach, used for example in field studies that rely on survey data, characterizes multifunctionality by the presence or absence of multiple services (Plieninger et al. 2013b), giving an indication of the service richness at a site. However, there is wide agreement that individual services are only beneficial if their supply meets a certain critical level (RaudseppHearne et al. 2010). Therefore, other approaches incorporate this condition and only count those services that exceed this critical level as a contribution to multifunctionality. For many services, such as water quality or carbon sequestration, critical levels can be derived from regulation standards or biogeophysical thresholds.

For the majority of services, however, no such universal thresholds are known or easy to incorporate. To circumvent this issue and to assure that a certain level of service supply is reached, it is possible to derive thresholds from cumulative distribution functions or quantiles of ES supply or biodiversity in multifunctionality assessments (Pasari et al. 2013; Allan et al. 2015). Here, only ES that exceed a threshold set at a particular $q$ quantile (e.g., $0.3,0.4, \ldots, 0.7)$ at a given site are included to quantify the multifunctionality of a site. In determining multifunctionality, the number of ES that exceed the chosen threshold are weighted equally, and variations in the level of ES supply are not accounted for.

An approach that aims to integrate the quantity of service supply is employed by Rodríguez-Loinaz et al. (2015). Their multiple ecosystem services landscape index (MESLI) sums ES scores normalized to lower and upper supply benchmarks that can conceptually be represented by thresholds and target levels of ES. In the absence of clear-defined thresholds, however, these levels are set to minimum and maximum observed values following

$M E S L I=\sum \frac{E S_{i j}-E s_{i \min }}{E S_{i \max }-E S_{i \min }}$

where ES represents $\mathrm{ES}_{i}$ supply at location $j$, and $\mathrm{ES}_{i}$ min and $\mathrm{ES}_{i} \max$ the minimum and maximum supply of $\mathrm{ES}_{i}$.

Table 1 Multifunctionality indicators applied in this study

\begin{tabular}{llllll}
\hline ID & Multifunctionality indicator & Short description & Range & Source \\
& & & Min & $\operatorname{Max}^{\mathrm{a}}$ & \\
\hline SRI & Simpson's Reciprocal Index & Diversity indicator & 1 & 12 & Raudsepp-Hearne et al. (2010) \\
SH & Shannon's $H^{\prime}$ & Diversity indicator & 0 & $\ln (12)$ & Plieninger et al. (2013b) \\
MESLI & MESLI & $\sum$ normalized ES & 0 & 12 & Rodríguez-Loinaz et al. (2015) \\
$\mathrm{T}_{30}-\mathrm{T}_{70}$ & Thresholds $\left(\mathrm{T}_{30}=30 \%\right.$-quantile) & $\sum$ ES $>q$-quantile & 0 & 12 & Allan et al. (2015) \\
\hline
\end{tabular}

${ }^{a}$ Based on the inclusion of $12 \mathrm{ES}$ and biodiversity indicators in the analysis 
The MESLI is very similar to the total ecosystem service value (TESV) applied by Maes et al. (2012). Both of these approaches, while valuable in discerning coldspots and hotspots of multiple ES supply, may bear the weakness that the resulting multifunctionality indicator may be skewed towards locations that feature few services in abundance, while disregarding the service richness that is commonly associated with multifunctionality.

Diversity indicators that aim to include both the service richness and their supply were originally introduced as a metric for biodiversity (Pielou 1966; Tramer 1969; Hill 1973). One of the most widely employed indicators is the Shannon's $H^{\prime}$. Shannon's $H^{\prime}$ quantifies multifunctionality by taking both the abundance of ES and their provision at a given location into account (Eq. 2).

$H^{\prime}=-\sum p_{i j} \ln p_{i j}$

where $H^{\prime}$ is Shannon's $H^{\prime}$, and $p_{\mathrm{ij}}$ represents the relative supply of $\mathrm{ES}_{i}$ at location $j$ relative to the total ES supply at location $j$.

The natural logarithm in the equation effects a relative reduction of the weight of very highly supplied ES compared to low supplied ES.

Another diversity indicator is the SRI. The SRI (Eq. 3) is a diversity indicator commonly used in biodiversity research but with some applications in ES research (Raudsepp-Hearne et al. 2010). Simpson's reciprocal index reflects the evenness of ES supply and gives more weight to service indicators that are highly supplied. It relates the relative supply of a particular service at a site to the total number of services.

$S R I=\frac{1}{\sum\left(n_{i j} / N\right)^{2}}$

where SRI is Simpson's reciprocal index, $n$ is the quantity of $\mathrm{ES}_{i}$ at location $j$, and $N$ is the number of $\mathrm{ES}$ considered.

Input data

\section{Ecosystem service models}

We used a set of indicators to quantify twelve ES and biodiversity indicators that are contributing to the multifunctionality of European landscapes (Table 2). The indicators represent provisioning $(n=2)$, regulating $(n=4)$, cultural $(n=3)$ and supporting ES and biodiversity $(n=3)$ at EU extent (excluding Croatia). All indicators are mapped at $1 \mathrm{~km}^{2}$ for the year 2000 and the year 2040 for two diverging future scenarios of simulated land use change. The ES indicators we used for this study are calculated from a range of biogeophysical, geographic and socioeconomic data, including information on land cover, and land management intensity. The models employed are based on simplified representations of the ecosystem processes underlying ES and biodiversity. In that sense, these models go beyond simply mapping ES based on the occurrence of land use types as commonly applied (Burkhard et al. 2009). When ES would be simply related to land use types, multifunctionality would just be dependent on the number of services provided by a particular land use type. The capacity of a land use type to provide services very much depends on the geophysical and socio-economic context as well as on the landscape structure, that is accounted for in many of the ES models employed. In the following, ES and biodiversity will be referred to as ecosystem services. Detailed descriptions of the modelling of ES indicators can be found in the Supplementary Material.

Multifunctionality assessments require normalization of ES maps to a common scale. Not all indicators are normally distributed, and some feature infrequent extreme values. To exclude extreme values from the analysis, we transformed the data by means of a $90 \%$ winsorization that set all values below the 5 th percentile and above the 95th percentile to these thresholds. To standardize between the reference year and the two future scenarios, for each ES, the thresholds used for the winsorization were computed accounting for all values from the three maps. To prevent underestimating these thresholds, only grid cells that can provide a particular ES were included in the calculations. Then, each ES map was normalized from 0 to 1 . To be able to assess multifunctionality at different spatial scales, we not only considered the original grid level of the ES maps, but also calculated for each ES map focal means of the normalized maps for six differently-sized square moving windows with variable radiuses $(1,2,5,10,25$ and $50 \mathrm{~km})$; for disambiguation, the analysis-scale on the original $1 \times 1 \mathrm{~km}$ grid level is referred to as ' $0 \mathrm{~km}$ ' in the following. Additionally, we considered the statistical units NUTS2 and the finer NUTS3 due to their 
Table 2 Overview of ecosystem services included in this study

\begin{tabular}{|c|c|c|c|c|}
\hline ID & Ecosystem service & Short description & Unit & Source \\
\hline \multicolumn{5}{|c|}{ Provisioning services } \\
\hline $\mathrm{CP}$ & Crop production & Energy content output & $\mathrm{MJ} / \mathrm{ha}$ & Pérez-Soba et al. (2015) \\
\hline $\mathrm{RE}$ & Raw material & Wood supply & $\mathrm{m}^{3} / \mathrm{km}^{2}$ & $\begin{array}{l}\text { Verkerk et al. (2011) and } \\
\text { Nabuurs et al. (2007) }\end{array}$ \\
\hline \multicolumn{5}{|c|}{ Regulating services } \\
\hline CS & Climate regulation & Carbon sequestration & $\mathrm{Mg} \mathrm{C} / \mathrm{km}^{2} /$ year & Schulp et al. (2008) \\
\hline FL & Flood regulation & Relative water retention & Dimensionless & Stürck et al. (2014) \\
\hline $\mathrm{PO}$ & Pollination & Area of habitat in vicinity of cropland & $\%$ of area & Serna-Chavez et al. (2014) \\
\hline $\mathrm{EC}$ & Erosion control & Protection against erosion & Dimensionless & Tucker et al. (2013) \\
\hline \multicolumn{5}{|c|}{ Cultural services } \\
\hline NT & Nature-based tourism & Potential for nature tourism & Dimensionless & van Berkel and Verburg (2011) \\
\hline WF & Wild food & Species & Number $/ \mathrm{km}^{2}$ & Schulp et al. (2014b) \\
\hline $\mathrm{RF}$ & Residential function & Population density & Pop. $/ \mathrm{km}^{2}$ & Bright et al. (2008) \\
\hline \multicolumn{5}{|c|}{ Supporting services $\&$ biodiversity } \\
\hline $\mathrm{CO}$ & Habitat connectivity & Proximity index & Dimensionless & Gustafson and Parker (1994) \\
\hline $\mathrm{AB}$ & Agro-biodiversity & Habitat suitability & Species $/ \mathrm{km}^{2}$ & Overmars et al. (2014) \\
\hline MF & Megafauna habitat & Habitat suitability for mammal species & Species $/ \mathrm{km}^{2}$ & van der Zanden (2016) \\
\hline
\end{tabular}

All indicators are available at EU extent at $1 \mathrm{~km}^{2}$ resolution for the year 2000 and the future scenarios V-A1 and V-B2

importance in planning processes and regional policy application within the EU. River catchments were also included to reflect an ecological rather than administrative unit. Computing the different ES indicators for various spatial scales and at several time steps resulted in a total of 360 ES maps used in this study.

\section{Land cover and land use intensity}

Land cover in the excluding Croatia (EU) in 2000 was based on CORINE land cover (CLC), spatially and thematically aggregated to $1 \mathrm{~km}^{2}$ and 16 categories (Verburg and Overmars 2009). Land use and land management indicators are dynamically simulated for the 2000-2040 period based on a series of models at a high spatial resolution of $1 \mathrm{~km}^{2}$ for two diverging scenarios (Stürck et al. 2015). These models account for global macro-economic developments, European policy, land use history, and local geophysical and socio-economic conditions. The modeling chain is described in more detail in Verburg et al. (2013) and Stürck et al. (2015). The land use and land management scenarios were input to the ES models and the multifunctionality indicators.

We simulated two diverging scenario storylines that resemble those employed by the IPCC Special
Report on Energy Scenarios (SRES) A1 and B2 (Nakicenovic and Swart 2000), but were elaborated to represent the EU context. The A1 storyline involves strong economic growth in a globalizing world with strong population growth, no incentives for climate change adaptation and weak regulation of land use change. The Common Agriculture Policy (CAP) is abolished in this scenario, leading to a discontinuation in EU subsidies and programs that strongly effect agricultural land use change in this scenario (e.g. through land abandonment in less suitable or marginal lands).

The B2 storyline represents a fragmented world with regional markets and modest economic growth, modest population growth, and regional implementation of environmental objectives. Under B2 conditions, the CAP is maintained.

Analyses of multifunctionality

We calculated multifunctionality indicators based on ES and biodiversity indicators to answer the following questions: (1) How much does the choice of multifunctionality indicator and scale of analysis influence multifunctionality results? (2) Does land use diversity significantly affect multifunctionality at a European 
scale? (3) How does multifunctionality in the EU change as result of the land use change scenarios?

Each of the four multifunctionality indicators presented in "Quantification of multifunctionality" section is used to quantify multifunctionality in the reference year 2000 and for the two scenarios in 2040. Considering that four different multifunctionality indicators are included and the sensitivity of five functional thresholds is tested, this resulted in 8 multifunctionality maps per year and scale of analysis (Fig. 1).

\section{Comparing multifunctionality indicators}

To gain insights into ways in which the choice of multifunctionality indicators influences results, we first retrieved Pearson's $r$ between multifunctionality indicators performed for a random sample of 1000 points across the EU. For analysis at the scale of administrative units or watersheds, we used the entire dataset to calculate correlations.

Secondly, we compared EU-wide aggregated averages of each indicator at each scale of analysis with the map comparison statistic (MCS, Schulp et al. 2014a) to evaluate the spatial correspondence of the different indicators. The MCS measures the correspondence between any two multifunctionality maps, where an MCS of 0 indicates perfect agreement and an MCS of 1 indicates complete disagreement between two maps. To calculate the MCS for each pairing of multifunctionality maps, we normalized the multifunctionality indicators to a range between 0 and 1 .

Finally, we compared the maps in terms of the identified hotspots and coldspots of multifunctionality

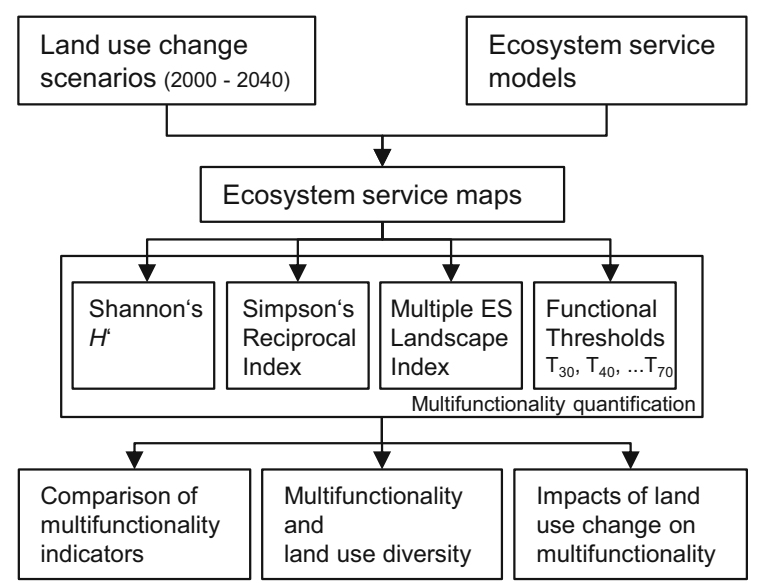

Fig. 1 Overview of the analyses across the EU. To do so, we classified the top and bottom $20 \%$ of grid cells (or zones) as indicated by each multifunctionality indicator as multifunctionality hotspot or coldspot. At each analysis scale, we overlaid these hot- and coldspots to find locations of high and low agreement between the indicators used in this study.

\section{The relationship between land use diversity and multifunctionality}

To assess the relationship between land use diversity and multifunctionality, we used Shannon's equitability $\left(E_{H}\right)$ to characterize the diversity of land use types in the landscape (Eq. 4).

$E_{H}=\frac{-\sum p_{i j} \ln p_{i j}}{\ln (N)}$

Where $E_{H}$ is Shannon's equitability, $p$ is the $\%$ cover of land use class $i$ within a fixed radius around location $j$ or within a zone $j$, and $N$ the number of land use classes.

This indicator ranges from 0 to 1 , where 1 represents complete evenness in the distribution of land use classes. We calculated $\mathrm{E}_{\mathrm{H}}$ for different analysis scales, including NUTS2 and NUTS3 regions, river catchments, and differently sized square moving windows analogous to the multifunctionality analysis scales. Based on a random sample of 1000 points, we calculated Pearson's $r$ for correlations between multifunctionality indicators and land use diversity $\left(E_{H}\right)$. Again, we used the entire dataset for analysis scales covering administrative units and river catchments. In a second step, we nuanced the analysis by looking at the same relationship separately for different landscape types. To do so, we selected, at each scale of analysis, landscapes that contain, respectively, $>50 \%$ agriculture, $>50 \%$ forests, $>50 \%$ built-up, and $>50 \%$ (semi-)natural land. We subset the landscape types to two groups. The first group displayed an $\mathrm{E}_{\mathrm{H}}$ greater than the $80 \%$ quantile, that we use here as a cut-of value to address land use diversity hotspots. The second group had an $\mathrm{E}_{\mathrm{H}}$ lower than $20 \%$ quantile that we used to define land use diversity coldspots. Whether multifunctionality in these two groups was significantly different ( $p$ value $<0.05)$ from each other was assessed with a $t$ test for each landscape type. 
Multifunctionality and land use change

To assess the effect of land use change on multifunctionality, we calculated EU-wide aggregated change according to each multifunctionality indicator at each analysis scale for both scenarios of land use change. Then, we visualized gains and losses in multifunctionality in the EU based on the relative change of multifunctionality between the years 2000 and 2040. Changes in multifunctionality were assessed at locations where different land use change trajectories take place. An overview of land use change trajectories (such as specific land conversions or land use intensity changes) as described in Stürck et al. (2015) is provided in the Supplementary Material.

\section{Results}

The role of multifunctionality indicators

We quantified the effect of the scale of analysis on EUscale average values of multifunctionality (Table 3; Table S2). Figure 2 contains multifunctionality maps for a selection of multifunctionality indicators at various spatial scales. The various indicators respond differently to the scale of analysis: where $\mathrm{T}_{30}$ and MESLI are least sensitive to the scale of analysis, SRI and Shannon's $H^{\prime}$ increase with increasing scale of analysis (Fig. 2). Multifunctionality decreases for $\mathrm{T}_{50}$, $\mathrm{T}_{60}$ and $\mathrm{T}_{70}$ with increasing analysis scale.

At the finest resolution, the majority of multifunctionality indicators suggest high multifunctionality in Scandinavia, Spain, Eastern France, South-Western Germany, and Romania. Consistent low levels are found in England, Northern Italy, and Northern France. At larger scales, dissimilarities between the maps increase. For example, at NUTS2 level, with SRI and $\mathrm{T}_{30}$, maxima are found in central Europe, while at $\mathrm{T}_{60}$, Scandinavia and southern European regions stand out. In contrast, at NUTS2 level, Shannon's $H^{\prime}$ and MESLI both level out intraregional differences that can be found at smaller analysis scales, resulting in a more homogeneous pattern of multifunctionality across Europe.

To assess the overall agreement between the different multifunctionality indicators, we calculated Pearson's $r$ for all pairings of multifunctionality indicators for each time step at each scale (Table 4). All results are provided in Table S3.

Shannon's $H^{\prime}$ and SRI showed correlations higher than 0.93 consistently throughout scales and time steps. The agreement of Shannon's $H^{\prime}$ with other indicators is significantly lower and agreement decreases with analysis scale. Negative correlations, as seen for example at NUTS2 level, indicate contrasting multifunctionality estimations between two indicators. Across all scales, the MESLI showed most frequently the highest agreement with the other indicators.

For all pairings of multifunctionality maps in each year at each analysis scale, we calculated the MCS. The MCS increased with increasing analysis scale, indicating that agreement in the spatial pattern of multifunctionality indicators decreased with increasing analysis scale (Table 5). All results are provided in Table S4.

Finally, we compared hotspots and coldspots (top and bottom $20 \%$ of grid cells) as identified by the various multifunctionality indicators (Fig. 3). Hotspots of multifunctionality (Fig. 3a-c) are generally in lower agreement between indicators across all scales than coldspots (Fig. 3d-f). The agreement of hotspot locations was particularly high at smaller analysis scales (radius $\leq 10 \mathrm{~km}$ ) and between similar indicators. Correspondence in multifunctionality hotspots declines with increasing scale of analysis.

In general, hotspots are associated with mountainous, forested lands on the grid level, most markedly in Germany, Austria, Romania and Scandinavia. Coldspots of multifunctionality are frequently found in landscapes dominated by agriculture, most markedly in Italy, Northern France and England. Also other homogenous landscapes, for example those dominated by pastures and (semi-)natural grasslands in Ireland and Scotland, show a high agreement of coldspots across all scales (Fig. 3d-f).

The relationship between land use diversity and multifunctionality

We quantified the relationship between land use diversity and multifunctionality. Correlations between a land use diversity indicator $\mathrm{E}_{\mathrm{H}}$ and multifunctionality indicators at various scales suggested only a weak relationship between land use diversity and multifunctionality (Table 6) with correlation coefficients 
Table 3 Average

multifunctionality for various multifunctionality indicators at various analysis scales (radius of analysis window in $\mathrm{km}$, or zone, respectively) in the EU in 2000

\begin{tabular}{lllllllllll}
\hline Indicator & 0 & 1 & 2 & 5 & 10 & 25 & 50 & Catchment & NUTS3 & NUTS2 \\
\hline SRI & 5.56 & 6.32 & 6.52 & 6.76 & 6.93 & 7.16 & 7.33 & 7.23 & 7.25 & 7.41 \\
SH & 1.79 & 1.96 & 2.00 & 2.04 & 2.07 & 2.11 & 2.13 & 2.11 & 2.12 & 2.14 \\
MESLI & 4.05 & 4.05 & 4.05 & 4.05 & 4.06 & 4.06 & 4.06 & 4.05 & 4.05 & 4.05 \\
$\mathrm{~T}_{30}$ & 5.62 & 6.03 & 6.09 & 6.22 & 6.39 & 6.63 & 6.77 & 6.68 & 6.70 & 6.79 \\
$\mathrm{~T}_{40}$ & 5.07 & 4.90 & 4.86 & 4.82 & 4.88 & 4.97 & 5.01 & 4.98 & 5.00 & 5.00 \\
$\mathrm{~T}_{50}$ & 4.40 & 3.93 & 3.71 & 3.48 & 3.40 & 3.35 & 3.29 & 3.28 & 3.36 & 3.27 \\
$\mathrm{~T}_{60}$ & 3.81 & 3.13 & 2.84 & 2.57 & 2.46 & 2.31 & 2.17 & 2.27 & 2.24 & 2.13 \\
$\mathrm{~T}_{70}$ & 1.61 & 1.26 & 1.17 & 1.03 & 0.91 & 0.71 & 0.52 & 0.61 & 0.56 & 0.34 \\
\hline
\end{tabular}

smaller than 0.1. With increasing analysis scale, even weak negative correlations are common, indicating negative relationships between land use diversity and multifunctionality. Figure 4 displays a transect in the United Kingdom, in which scale-dependent land use diversity and multifunctionality according to several indicators are presented. Clearly, the different indicators feature partly opposing relationships with land use diversity. Only the MESLI seems to indicate lower multifunctionality where land use diversity drops along the transect.

We also tested the effect of land use diversity on multifunctionality for different landscape types based on the landscape composition, i.e. agriculture-, forest-, nature-, and urban-dominated landscapes $(\geq 50 \%$ of coverage within the analysis window). Results for agriculture- and forest-dominated landscapes are indicated in Fig. 5a and b, respectively.

The $t$ test results indicate that in most cases, landscapes that differ in their land use diversity also differ significantly in their multifunctionality, though the relationship is less clear on larger analysis scales. We found that the relationship between land use diversity and multifunctionality differs for different landscape types. For example, homogenous agricultural landscapes (i.e., displaying a low $\mathrm{E}_{\mathrm{H}}$ ) yield significantly lower multifunctionality than more mosaic agricultural landscapes (Fig. 5a). While this effect is consistent across scales, it does not apply to the functional thresholds $\left(\mathrm{T}_{30}\right.$ to $\left.\mathrm{T}_{70}\right)$. Multifunctionality in forest-dominated landscapes shows a different relationship to land use diversity, where, instead, land use diversity coldspots are associated with higher multifunctionality scores for the MESLI and $\mathrm{T}_{40}$ (Fig. 5b).

For the tested analysis scales, the average multifunctionality indicator in land use diversity hotspots and coldspots differed significantly from the average multifunctionality for forest-dominated landscapes. However, no consistent relationship between land use diversity and multifunctionality can be observed. All results are detailed in Table S5.

The impact of land use change for future landscape multifunctionality

We quantified the effect of the land change scenarios on multifunctionality. Figure 6 exemplarily shows changes in multifunctionality between the year 2000 and 2040 for the V-B2 scenario. Results for the V-A1 scenario can be found in Figure $S 1$. Land use change in both future scenarios suggests slight increases in the overall multifunctionality according to indicators defined by a threshold above the $40 \%$-quantile $\left(\mathrm{T}_{40^{-}}\right.$ $\mathrm{T}_{70}$ ) and the MESLI. The increase in multifunctionality is consistent throughout scales of analysis. Shannon's $H^{\prime}$ and the SRI, however, slightly decreased in time. The overall change in multifunctionality is smaller when the analysis is made at a broader spatial scale (Fig. 6). This indicates that at the regional scale, local losses in multifunctionality are compensated for at intraregional level. For the V-B2 scenario, two consistent, regional trends can be distinguished. Agricultural dominated landscapes in Northern France and Southern UK, as well as regions with strong urban growth in the Netherlands, Belgium and Germany, consistently lose multifunctionality according to all tested indicators and across all scales of analysis. Gains in multifunctionality emerge in the northern UK, Scandinavia, Northern Spain, Italy, and Greece. This development is linked to reforestation and deintensification trends in agriculture.

The impact of individual land use changes on multifunctionality was assessed by calculating the 

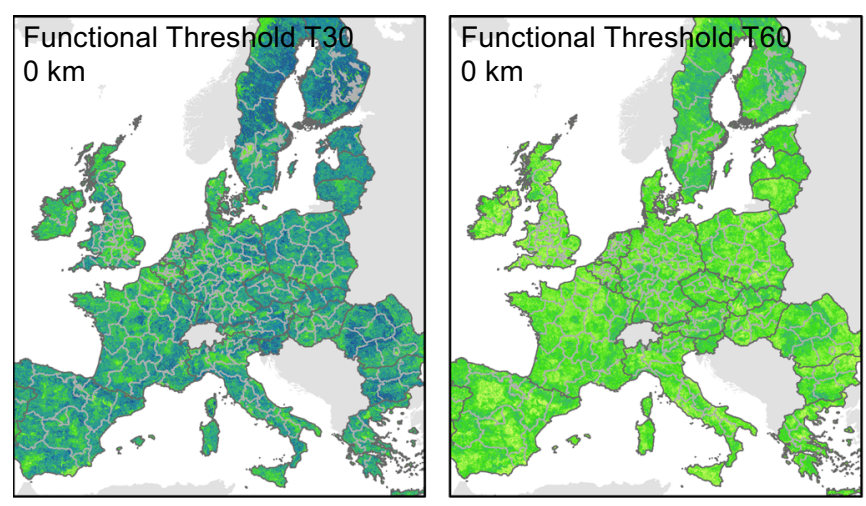

\section{Multifunctionality score}
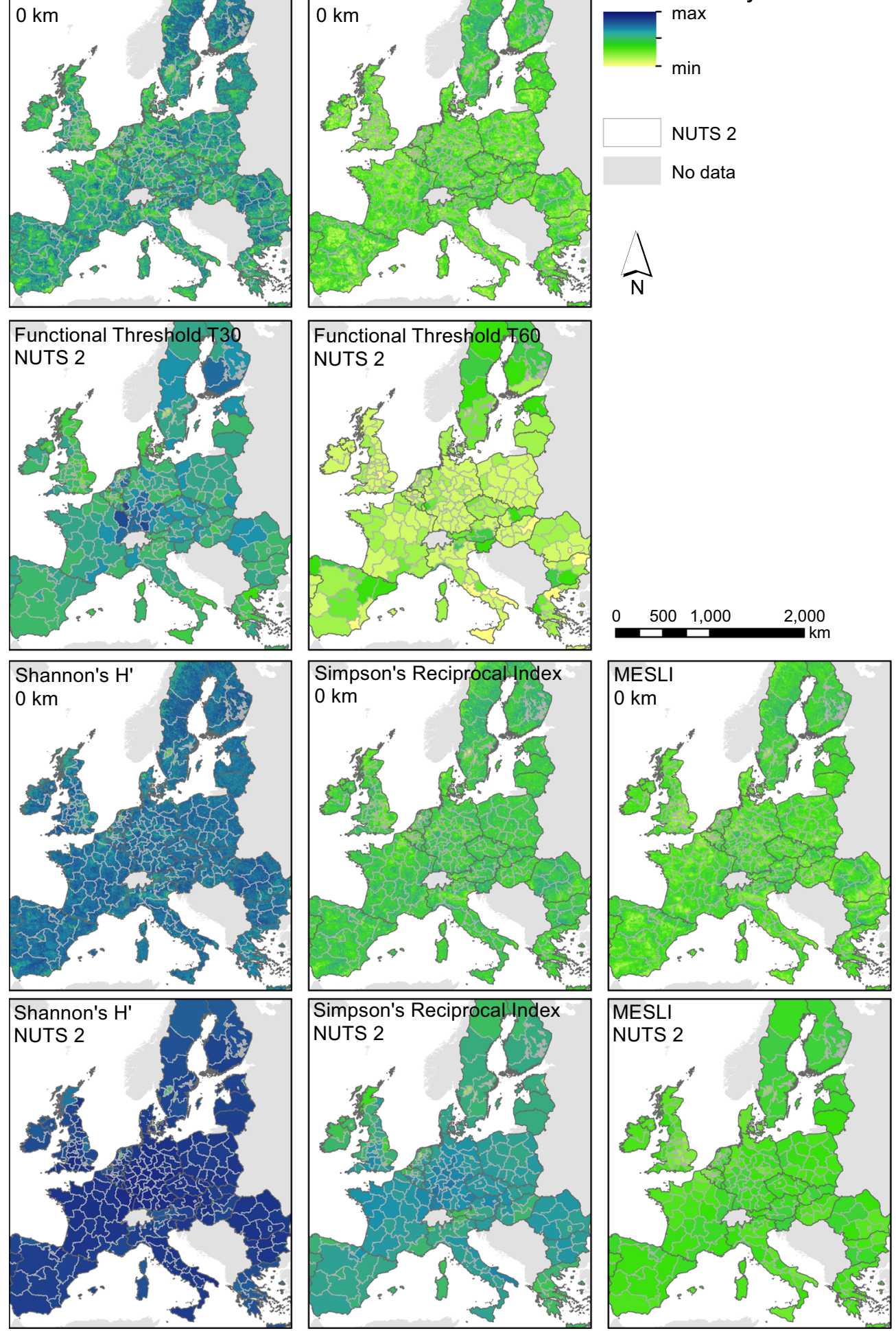

Fig. 2 Multifunctionality in the EU according to various indicators at various analysis scales in the year 2000 
Table 4 Correlation between multifunctionality indicators at various analysis scales (radius of analysis window in $\mathrm{km}$, or zone, respectively) in the EU in 2000
Table 5 Map comparison statistic (MCS) for pairings of multifunctionality maps at various analysis scales (radius of analysis window in $\mathrm{km}$, or zone, respectively) in the EU in 2000

\begin{tabular}{lllllllllll}
\hline Radius & Indicator & SRI & SH & MESLI & $\mathrm{T}_{30}$ & $\mathrm{~T}_{40}$ & $\mathrm{~T}_{50}$ & $\mathrm{~T}_{60}$ & $\mathrm{~T}_{70}$ & Radius \\
\hline 0 & SRI & & 0.94 & 0.57 & 0.70 & 0.59 & 0.42 & 0.25 & 0.21 & 1 \\
& SH & 0.95 & & 0.42 & 0.60 & 0.44 & 0.25 & 0.08 & 0.04 & \\
& MESLI & 0.82 & 0.70 & & 0.76 & 0.77 & 0.80 & 0.77 & 0.74 & \\
& $\mathrm{~T}_{30}$ & 0.84 & 0.78 & 0.83 & & 0.80 & 0.68 & 0.55 & 0.40 & \\
& $\mathrm{~T}_{40}$ & 0.80 & 0.72 & 0.82 & 0.90 & & 0.83 & 0.68 & 0.49 & \\
& $\mathrm{~T}_{50}$ & 0.74 & 0.64 & 0.81 & 0.81 & 0.89 & & 0.84 & 0.62 & \\
& $\mathrm{~T}_{60}$ & 0.67 & 0.57 & 0.81 & 0.74 & 0.80 & 0.88 & & 0.75 & \\
& $\mathrm{~T}_{70}$ & 0.60 & 0.47 & 0.80 & 0.60 & 0.60 & 0.64 & 0.73 & & \\
NUTS3 & SRI & & 0.95 & 0.17 & 0.43 & 0.28 & -0.05 & -0.16 & -0.17 & 25 \\
& SH & 0.95 & & 0.04 & 0.37 & 0.14 & -0.20 & -0.31 & -0.32 & \\
& MESLI & 0.56 & 0.48 & & 0.69 & 0.78 & 0.81 & 0.75 & 0.63 & \\
& $\mathrm{~T}_{30}$ & 0.63 & 0.58 & 0.78 & & 0.71 & 0.46 & 0.34 & 0.19 & \\
& $\mathrm{~T}_{40}$ & 0.56 & 0.46 & 0.80 & 0.77 & & 0.68 & 0.57 & 0.37 & \\
& $\mathrm{~T}_{50}$ & 0.24 & 0.14 & 0.76 & 0.53 & 0.66 & & 0.85 & 0.63 & \\
$\mathrm{~T}_{60}$ & 0.06 & -0.03 & 0.61 & 0.34 & 0.47 & 0.78 & & 0.74 & \\
& $\mathrm{~T}_{70}$ & -0.19 & -0.25 & 0.29 & 0.00 & 0.09 & 0.41 & 0.60 & & \\
\hline
\end{tabular}

\begin{tabular}{lllllllllll}
\hline Radius & Indicator & SRI & SH & MESLI & $\mathrm{T}_{30}$ & $\mathrm{~T}_{40}$ & $\mathrm{~T}_{50}$ & $\mathrm{~T}_{60}$ & $\mathrm{~T}_{70}$ & Radius \\
\hline 0 & SRI & & 0.32 & 0.17 & 0.09 & 0.12 & 0.19 & 0.27 & 0.45 & 1 \\
& SH & 0.35 & & 0.47 & 0.30 & 0.40 & 0.48 & 0.55 & 0.72 & \\
& MESLI & 0.12 & 0.43 & & 0.18 & 0.11 & 0.09 & 0.14 & 0.37 & \\
& $\mathrm{~T}_{30}$ & 0.09 & 0.28 & 0.16 & & 0.10 & 0.19 & 0.26 & 0.43 & \\
& $\mathrm{~T}_{40}$ & 0.08 & 0.34 & 0.11 & 0.05 & & 0.10 & 0.18 & 0.36 & \\
& $\mathrm{~T}_{50}$ & 0.10 & 0.40 & 0.09 & 0.12 & 0.07 & & 0.09 & 0.30 & \\
& $\mathrm{~T}_{60}$ & 0.15 & 0.45 & 0.08 & 0.18 & 0.13 & 0.07 & & 0.23 & \\
& $\mathrm{~T}_{70}$ & 0.41 & 0.66 & 0.31 & 0.40 & 0.35 & 0.31 & 0.24 & & \\
NUTS3 & SRI & & 0.31 & 0.28 & 0.09 & 0.20 & 0.36 & 0.47 & 0.64 & 25 \\
& SH & 0.31 & & 0.54 & 0.31 & 0.46 & 0.60 & 0.70 & 0.84 & \\
& MESLI & 0.32 & 0.57 & & 0.23 & 0.13 & 0.17 & 0.26 & 0.53 & \\
& $\mathrm{~T}_{30}$ & 0.10 & 0.34 & 0.26 & & 0.15 & 0.30 & 0.39 & 0.54 & \\
& $\mathrm{~T}_{40}$ & 0.24 & 0.50 & 0.12 & 0.18 & & 0.18 & 0.30 & 0.47 & \\
& $\mathrm{~T}_{50}$ & 0.42 & 0.65 & 0.17 & 0.35 & 0.19 & & 0.15 & 0.38 & \\
& $\mathrm{~T}_{60}$ & 0.54 & 0.75 & 0.29 & 0.46 & 0.30 & 0.15 & & 0.23 &
\end{tabular}

average multifunctionality indicator for locations where a certain land change trajectory is projected in the V-B2 scenario in 2040 (Table 7). Results for the $\mathrm{V}-\mathrm{A} 1$ scenario can be found in Table S6. We visualized the impact on individual ES using radar diagrams for each of the typical land change trajectories (Fig. 7) and assessed the significance of change between the start and end year using $t$ tests ( $p$ value $<0.05)$. Land changes that negatively affect multifunctionality in both scenarios are peri-urban and urban growth, and the intensification of pastures. Particularly locations in the UK, Belgium and the Netherlands are affected by these trajectories. In Poland, for example, losses of multifunctionality can be associated to cropland intensification. Positive impacts of land change on multifunctionality can be 

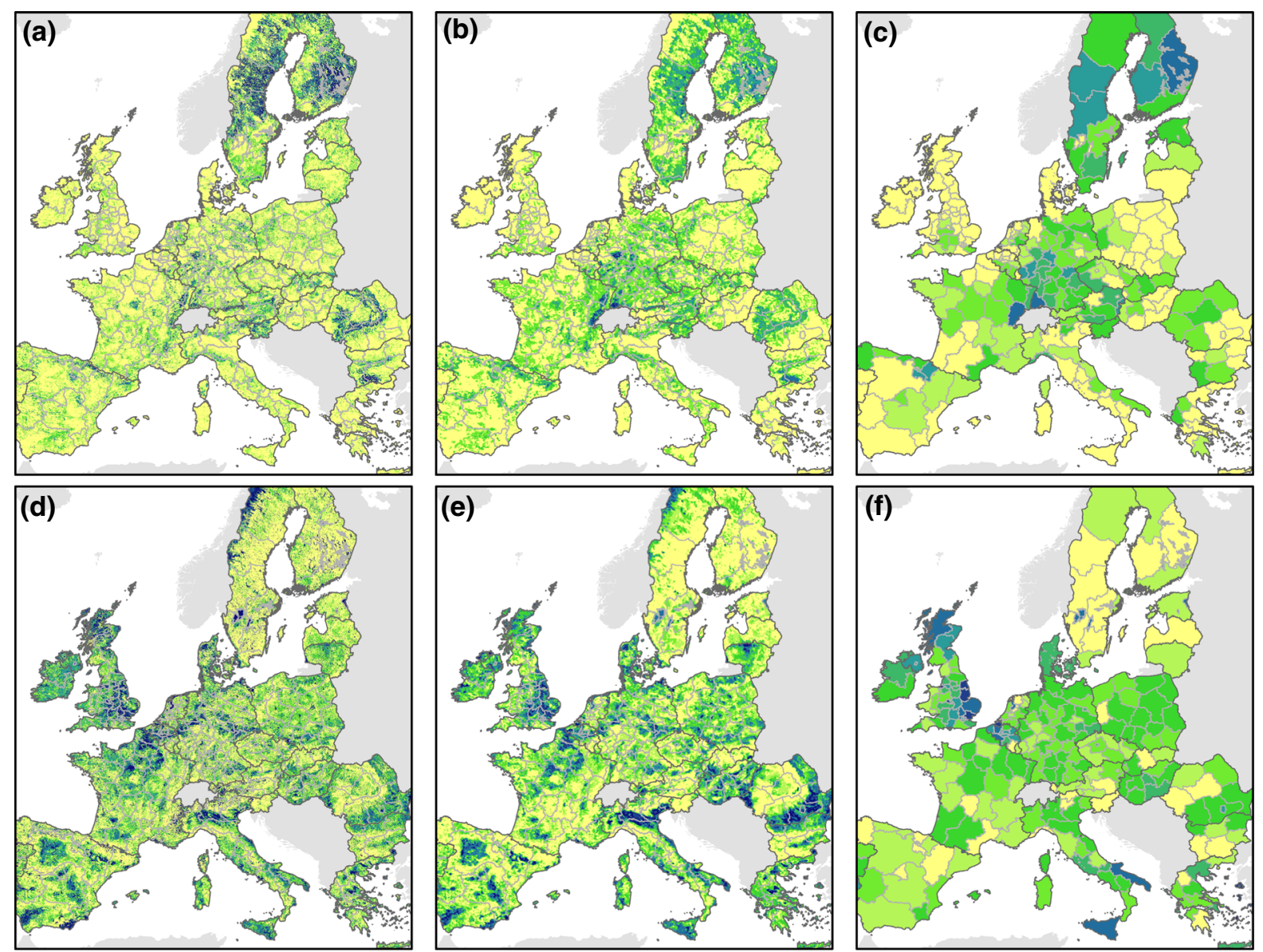

No. of hotspots and coldspots
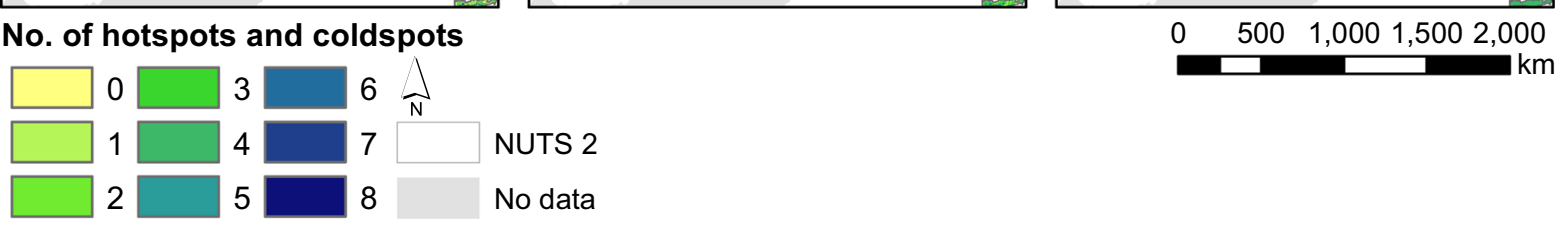

Fig. 3 Number of overlaps of multifunctionality hotspots across multifunctionality indicators at analysis scales with radius of a $0 \mathrm{~km}$, b $5 \mathrm{~km}$, and c NUTS2 regions, and number of overlaps of multifunctionality coldspots at $\mathbf{d} 0 \mathrm{~km}$, e $5 \mathrm{~km}$, and $\mathbf{f}$ NUTS2 regions in 2000

associated to pasture de-intensification, cropland deintensification, and conversion of cropland to pasture (Fig. 7).

Other land change impacts vary more depending on the ES considered. For example, recultivation of green space increases the supply of agriculture-related services, but entails losses in regulating services and biodiversity. Expansion of large-scale nature leads to a broader supply of regulating and cultural services, but results in the loss of productive functions. These changes are reflected ambiguously by the different multifunctionality indicators (Table 7). Land use change, particularly broad conversions to another land system, result in large trade-offs between ES. Land abandonment entails losses in agricultural dependent services, but increases nearly all other ES. However, also the landscape in which land abandonment occurs is important. In the proximity of large-scale nature, MESLI increases slightly, while otherwise, land abandonment results in slight multifunctionality losses. De-intensification in agricultural systems is associated with subtle gains in multifunctionality without drastic losses in any ES provided. Radar diagrams depicting changes in ES supply by land 
Table 6 Correlations between multifunctionality indicators at various scales (radius of analysis window in km, or zone, respectively) and a land use diversity indicator $\mathrm{E}_{\mathrm{H}}$ in 2000

\begin{tabular}{|c|c|c|c|c|c|c|c|c|c|}
\hline Indicator & 1 & 2 & 5 & 10 & 25 & 50 & catchment & NUTS3 & NUTS2 \\
\hline SRI & 0.01 & 0.01 & 0.01 & 0.01 & -0.01 & -0.04 & 0.01 & $-0.08^{*}$ & $-0.10^{*}$ \\
\hline SH & 0.01 & 0.02 & 0.03 & 0.04 & 0.03 & 0.00 & 0.03 & $-0.08^{*}$ & $-0.07 *$ \\
\hline MESLI & -0.02 & -0.02 & -0.05 & $-0.08 *$ & $-0.15^{*}$ & $-0.20^{*}$ & $-0.09 *$ & $-0.12 *$ & $-0.18^{*}$ \\
\hline $\mathrm{T}_{30}$ & -0.01 & -0.01 & -0.04 & $-0.07 *$ & $-0.14^{*}$ & $-0.23^{*}$ & $-0.11 *$ & $-0.16^{*}$ & $-0.29 *$ \\
\hline $\mathrm{T}_{40}$ & 0.00 & -0.03 & $-0.06^{*}$ & $-0.11 *$ & $-0.14^{*}$ & $-0.20 *$ & $-0.09 *$ & $-0.14 *$ & $-0.22^{*}$ \\
\hline $\mathrm{T}_{50}$ & -0.01 & -0.04 & -0.05 & $-0.09 *$ & $-0.13 *$ & $-0.12 *$ & -0.05 & -0.03 & -0.02 \\
\hline $\mathrm{T}_{60}$ & -0.02 & -0.04 & -0.04 & $-0.08^{*}$ & $-0.13^{*}$ & $-0.13 *$ & $-0.08^{*}$ & $-0.07 *$ & $-0.07 *$ \\
\hline $\mathrm{T}_{70}$ & -0.03 & -0.02 & -0.02 & -0.04 & $-0.07 *$ & $-0.12 *$ & $-0.08 *$ & -0.05 & $-0.09 *$ \\
\hline
\end{tabular}

Correlations significant with $\mathrm{p}<0.05$ are marked with an asterisk

change trajectory for the V-A1 scenario can be found in Figure S2.

\section{Discussion}

Limitations and possibilities of quantifying multifunctionality

In the literature, there is no consistency in the methods used to quantify multifunctionality of land use. Therefore, we tested various approaches to quantify multifunctionality developed or employed in recent studies. Each of the indicators highlights specific aspects of multifunctionality.

Quantile-based thresholds help to find locations that provide a vast number of ES that are supplied above a certain value. In this form, it is a simple, straight-forward tool that translates into a comparable multifunctionality indicator. However, the higher the chosen threshold, fewer locations provide multiple ES at that quantity (Table 2). High values of such an indicator tend to point towards locations that provide few services abundantly, while the status of the other services is entirely disregarded. In contrast, when the threshold is set at a low level, the severe depletion of one service could be easily offset by comparatively small gains of another service (Table 7), which hampers the informative value of this indicator.

The MESLI indicator, in turn, is strongly affected by the level of supply of individual services. Because it takes into account the entire distribution of ES in one site, it is an apt tool to gain an overview of the overall level of service provision. It can accurately depict the level of change in multifunctionality, for example as a result of land use change. However, due to the lack of minimum thresholds for many ES, it is necessary to investigate the individual services to ascertain whether high multifunctionality values are a result of few highly supplied services, or if the services are more evenly supplied. When interpreting change, this indicator does not differentiate between losses in an ES that has a high supply or a low supply (leading to a decrease in service richness).

Shannon's $H^{\prime}$ limits the weight of highly supplied ES within the multifunctionality analysis, and thus, accentuates the presence of rare, or lowly supplied, ES that support the overall ES diversity. Our results indicate that Shannon's $H^{\prime}$ has particularly low values in homogenous landscapes. As such, it is a highly scale-dependent indicator that requires careful interpretation.

Simpson's Reciprocal Index accentuates the occurrence of very highly supplied ES within a landscape. As it takes into account both the ES supply and the evenness of the supply across ES, it has shown to be particularly pronounced at agricultural fringes (Fig. 8).

While each of the indicators has its virtue, they also entail a range of limitations, and the results of our assessment show that it is of utmost importance to bear the multifunctionality indicator's characteristics in mind while interpreting the results. Relying on a single indicator may lead to results that only address a single element of multifunctionality. Particularly when analyzing change in multifunctionality, it is shown that 


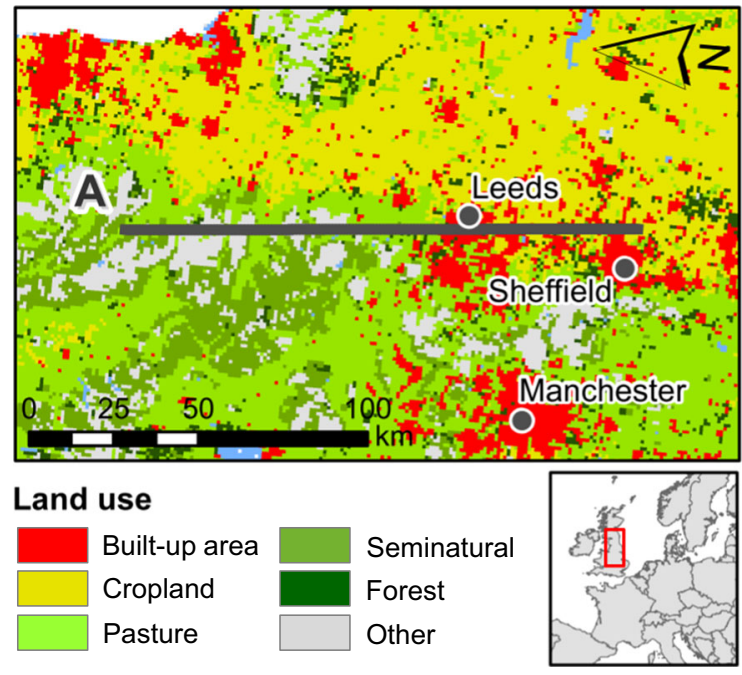

(a)

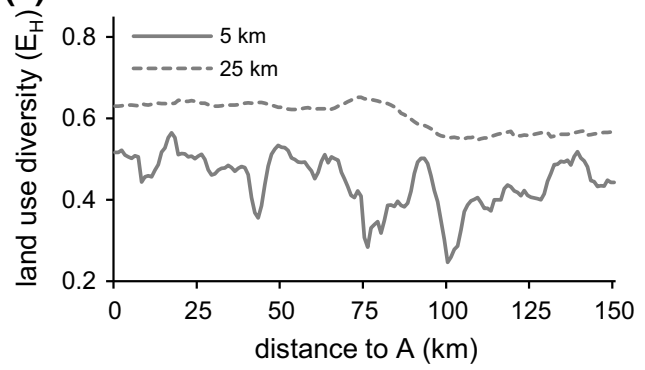

(b)

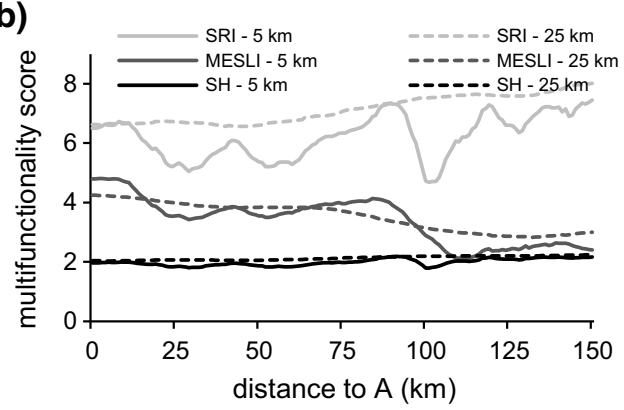

Fig. 4 a Land use diversity and $\mathbf{b}$ Multifunctionality according to several multifunctionality indicators at different analysis scales along a transect in 2000

the different indicators can lead to different conclusions. It is questionable if there is one singular indicator used in recent literature that is apt to solely base land management decisions upon, or that could replace the thorough investigation of the individual ES that a location comprises. As pointed out by Hansen and Pauleit (2014), solely aiming to improve a landscape's multifunctionality score bears the risk of disregarding the depletion of single ES that have little effect on multifunctionality, but that are fundamental to ecosystem well-being. In particular, in the case of tele-connected effects of ES (Liu et al. 2013), the contribution of individual ES to multifunctionality is convoluted and almost impossible to discern with approaches that are currently employed. We found that the scale of analysis significantly impacts the spatial configuration and overall magnitude of multifunctionality, yet each multifunctionality indicator showed an individual response (Table 3). $\mathrm{T}_{30}$ as a quantile-based indicator with a low threshold "profits" from larger analysis scales because multiple different ecosystems in the landscape may synchronously provide different services, while at higher spatial resolutions, ES are separated in different units of analysis. The higher the chosen threshold, however, the smaller the likelihood for distinct ecosystems to feature a wide range of ES that also surpass the chosen threshold. For Shannon's $H^{\prime}$ and SRI, however, thresholds do not apply, and thus both, on average, increase with increasing scale of analysis. The MESLI, focusing on the sum of normalized ES supply, is fairly consistent over various spatial scales.

Land use change in the EU and its role for multifunctional landscapes

In this study we have chosen for a wide range of ES and biodiversity indicators to contribute to multifunctionality because in many landscapes, both ES supply and biodiversity conservation are important objectives that do not necessarily coincide (Bullock et al. 2011; Mace et al. 2012). While ecosystem services are central to human well-being, biodiversity is not only inherently valuable, but also affects the underlying ecosystem service functioning (Cardinale et al. 2012). ES and biodiversity both represent the diversity of functions in the landscape that we tried to integrate in our approach and therefore, we have chosen to base multifunctionality on both ES and biodiversity indicators.

We simulated land use change based on two scenarios that represent different political, socioeconomic and technological pathways. These pathways influence the frequency of particular land change trajectories and their spatial occurrence across the EU. In the V-A1 scenario, the abolition of the Common Agricultural Policy causes high ratios of land abandonment, particularly in Southern Europe. This, of 

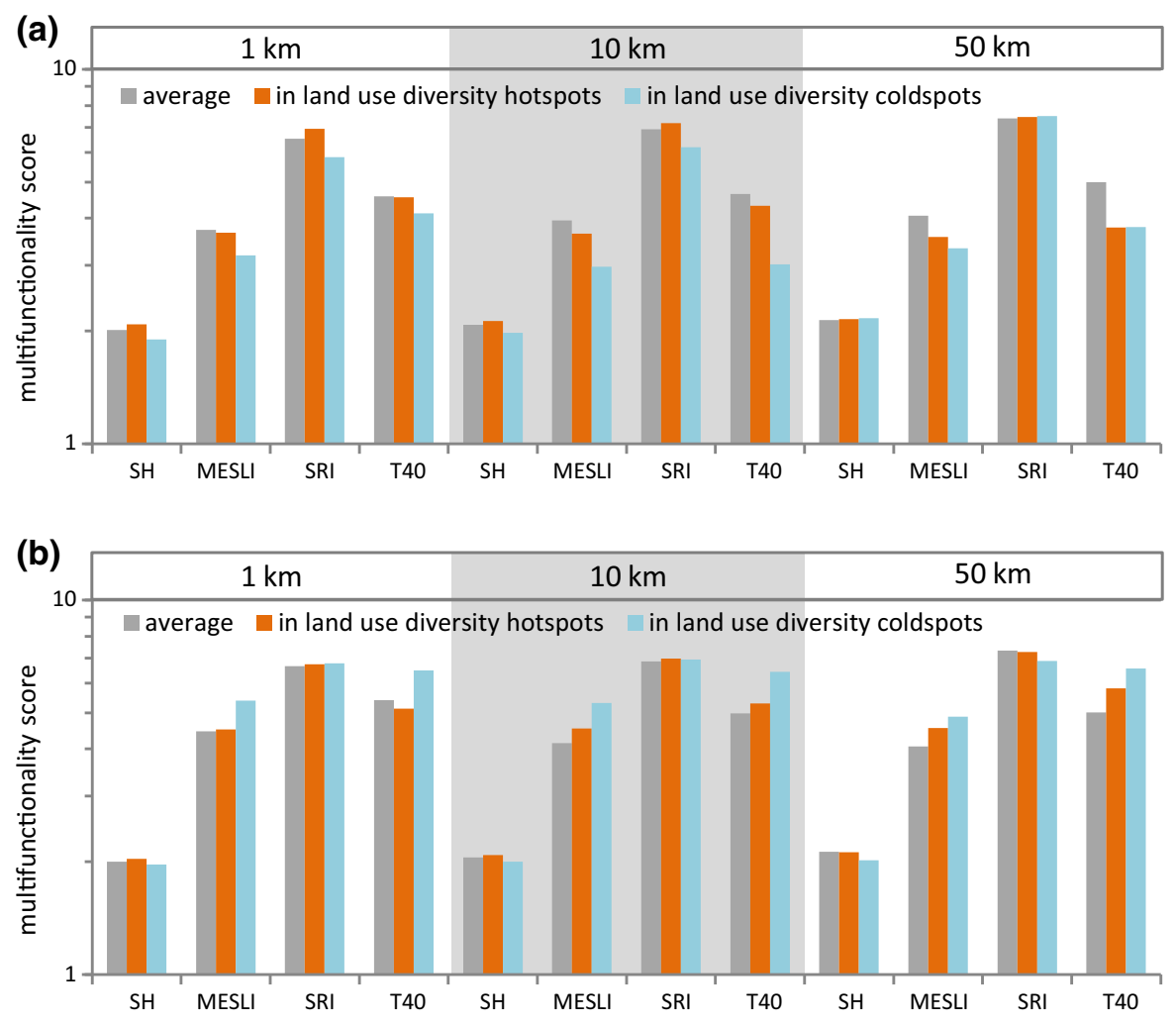

Fig. 5 Variation of multifunctionality indicators with respect to analysis scale, dominant land cover, and land use diversity for the year 2000 for a landscapes dominantly composed of

course, entails drastic effects on agricultural production, but also farm-related services and agro-biodiversity (Rey Benayas 2007), and is, in our results, predominantly associated to multifunctionality loss across the EU (Table 7). However, as shown in Fig. 7a, land abandonment can also be considered as a chance by increasing regulating and cultural services as well as habitat functions and biodiversity (megafauna habitat) in context of the wider landscape configuration (Cerqueira et al. 2015). These locationdependent results are indicative for the locationspecific impacts of particular land use changes on multifunctionality across the EU territory.

We also found that locations of urban growth and peri-urban growth are often characterized by comparatively low multifunctionality scores. These trajectories are bound to the vicinity of larger urban agglomerations, and therefore, also reflect the currently low level of multifunctionality in the neighborhood of agglomerations and the rural-urban fringe (e.g., Fig. 7b). agriculture and $\mathbf{b}$ landscapes dominantly composed of forested land. Deviations from the mean are significant with $\mathrm{p}<0.05$

Overall, the results of the scenarios show a spatially variable palette of multifunctionality responses. The small aggregated changes at EU scale do not represent the much larger changes within specific regions and localities that are a result of the many land use changes simulated under the scenarios. Assessments of location-specific impacts on the various dimensions of multifunctionality therefore remain important.

\section{Methodological limitations of the study}

This study has relied on the application of a wide range of existing modelling tools to assess ES and land use change at the EU scale. Although these methods have been applied before, they all contain an inherent range of uncertainty, often described in the source publications of the individual methods. Particularly the EUwide methods for ES quantification show large variations when compared to other models (Schulp et al. 2014a). 

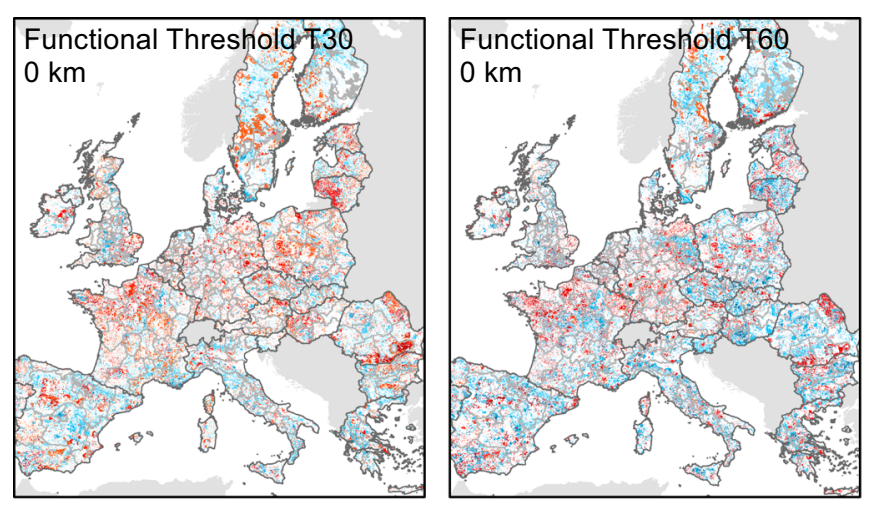

relative change $(\%)$
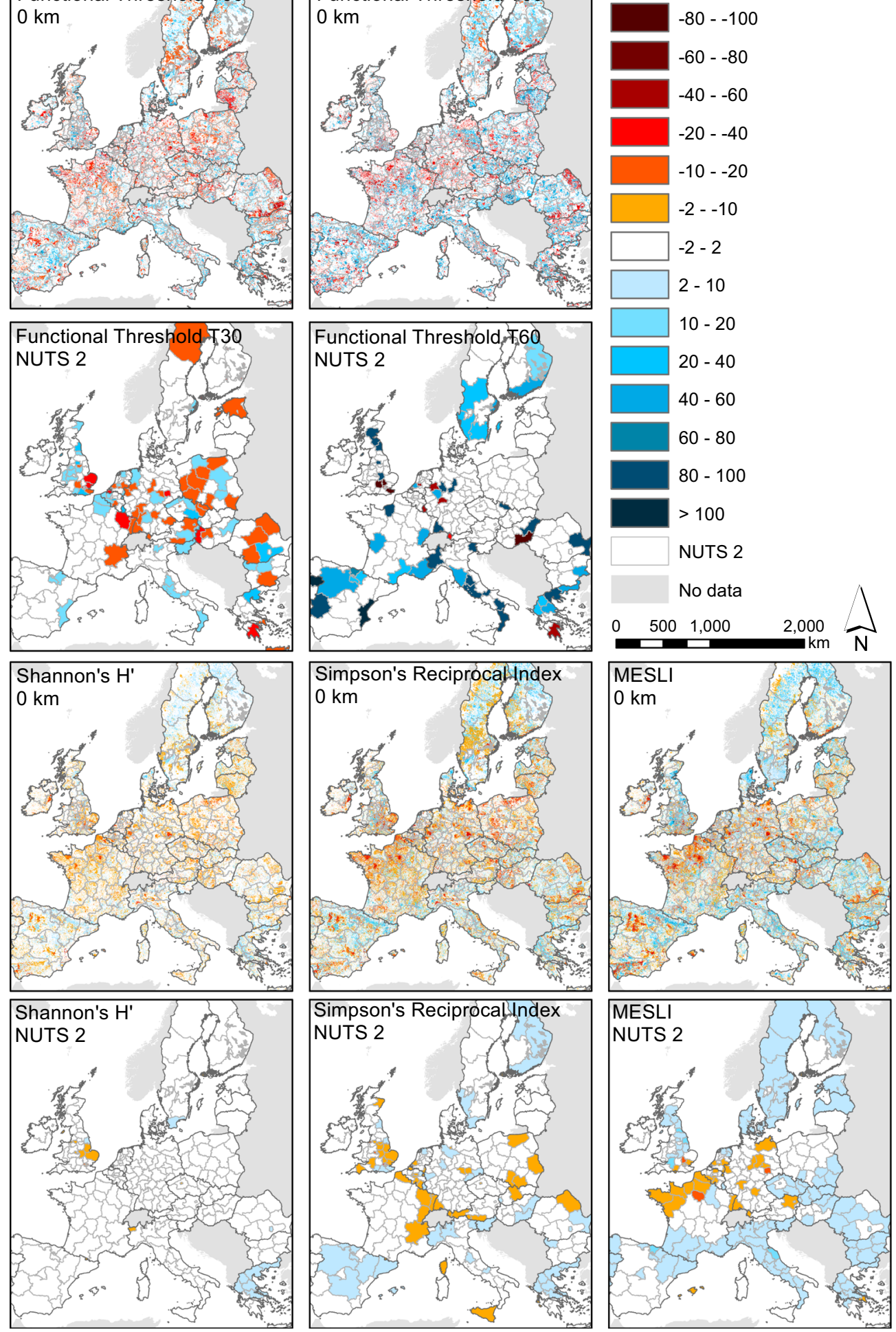

Fig. 6 Relative change (\%) of multifunctionality in the EU in V-B2 between the years 2000 and 2040 
Table 7 Average multifunctionality according to multifunctionality indicators in 2000 and relative change (\%) in 2040 (V-B2) at locations of particular land change trajectories

\begin{tabular}{|c|c|c|c|c|c|c|c|c|}
\hline Land change trajectory & $\mathrm{T}_{30}$ & $\mathrm{~T}_{40}$ & $\mathrm{~T}_{50}$ & $\mathrm{~T}_{60}$ & $\mathrm{~T}_{70}$ & MESLI & SH & SRI \\
\hline Urban growth & $4.91(-26)$ & $4.30(-24)$ & $3.72(-18)$ & $3.15(-13)$ & $1.13(-34)$ & $3.54(-25)$ & $1.80(-19)$ & $5.39(-32)$ \\
\hline Peri-urban growth & $5.27(-39)$ & $4.65(-38)$ & $4.02(-38)$ & $3.41(-34)$ & $1.29(-80)$ & $3.74(-33)$ & $1.84(-26)$ & $5.62(-42)$ \\
\hline $\begin{array}{l}\text { Land abandonment } \\
\text { (contributing to } \\
\text { large-scale nature) }\end{array}$ & $6.19(-9)$ & $5.76(-8)$ & $5.09(-5)$ & $4.60(-3)$ & $2.07(18)$ & $4.57(2)$ & $1.87(-6)$ & $6.02(-8)$ \\
\hline $\begin{array}{l}\text { Cropland to pasture } \\
\text { conversion }\end{array}$ & $5.82(1)$ & $5.10(3)$ & $4.20(10)$ & $3.58(10)$ & $1.56(0)$ & $3.63(22)$ & $1.84(5)$ & $5.52(15)$ \\
\hline $\begin{array}{l}\text { Pasture to cropland } \\
\text { conversion }\end{array}$ & $5.64(-7)$ & $5.08(-8)$ & $4.37(-9)$ & $3.73(-10)$ & $1.41(-16)$ & $4.17(-19)$ & $1.92(-6)$ & $6.15(-13)$ \\
\hline $\begin{array}{l}\text { Pasture de- } \\
\text { intensification }\end{array}$ & $5.70(4)$ & $4.68(12)$ & $3.80(31)$ & $3.02(39)$ & $0.95(85)$ & $3.95(18)$ & $1.93(1)$ & $6.08(5)$ \\
\hline Pasture intensification & $5.99(-3)$ & $5.56(-6)$ & $5.30(-23)$ & $4.57(-26)$ & $1.91(-34)$ & $4.67(-14)$ & $1.94(-2)$ & $6.41(-6)$ \\
\hline $\begin{array}{l}\text { Cropland de- } \\
\text { intensification }\end{array}$ & $4.90(20)$ & $4.30(23)$ & $3.76(16)$ & $3.25(16)$ & $1.18(36)$ & $3.32(12)$ & $1.77(4)$ & $5.17(10)$ \\
\hline $\begin{array}{l}\text { Cropland } \\
\text { intensification }\end{array}$ & $6.17(-18)$ & $5.40(-16)$ & $4.43(-13)$ & $3.67(-13)$ & $1.36(-24)$ & $3.73(-9)$ & $1.88(-5)$ & $5.82(-10)$ \\
\hline $\begin{array}{l}\text { Recultivation of green } \\
\text { space }\end{array}$ & $4.93(2)$ & $4.40(1)$ & $3.87(-2)$ & $3.39(-5)$ & $1.52(-21)$ & $3.93(-11)$ & $1.70(6)$ & $5.07(6)$ \\
\hline
\end{tabular}

Multifunctionality results should, therefore, be interpreted as being indicative while absolute values may be subject to uncertainty. Another source of uncertainty derives from the selection of indicators we chose. Not all ES can be represented in the analysis due to a lack of appropriate quantification methods and/or a limited relevance of some ES. We chose a set of indicators that covers a wide range of ES types, such as provisioning, regulating, cultural and supporting services, and biodiversity, to address multifunctionality in a broad sense and to avoid the resulting multifunctionality indicators being biased towards a particular service type. Yet, the choice of ES included in the analysis largely impacts the resulting multifunctionality, and changes or additions to the set of indicators will definitely alter the results.

Particularly in assessing land use change impacts on multifunctionality, the choice of ES will affect the result as land use change often results in trade-offs between different ES types, such as provisional and regulating ES.

Furthermore, it is important to understand what the respective ES models are able to quantify, i.e. potential supply, or use (ES flows). In our case, only few models (e.g., pollination) capture ES flows, while others do not take the use or demand side into account.
Without having knowledge about the demand side, however, and without explicitly taking spatio-temporal trade-offs between ES into account when modelling ES supply (or use), multifunctionality maps as prepared here cannot be used to indicate the sustainability of a given land use.

Implications for land management and further research

In many policy documents, the achievement of multifunctional land use is mentioned without specification of which aspects of multifunctionality, such as service richness or diversity across ES types, are targeted. Implementation of land management and management of land change require a more specific understanding of the scales at which multifunctionality should be achieved and what aspects of multifunctionality are given priority (Raudsepp-Hearne and Peterson 2016). Such will allow an evaluation of alternatives, ex-ante assessment of land use options as well as monitoring.

Our results show that high levels of land use diversity do not necessarily correspond to high levels of multifunctionality. Different land use types do supply different ES, but, particularly when the level of 
Fig. 7 Average ecosystem service composition at locations of land change, in the year 2000 and in 2040 (V-B2 scenario) based on normalized ES: a land abandonment contributing to growth of large-scale nature, b peri-urban growth, c urban growth, $\mathbf{d}$ pasture de-intensification, e cropland to pasture conversion, $\mathbf{f}$ recultivation of green space, $\mathbf{g}$ cropland de-intensification, $\mathbf{h}$ cropland intensification and $\mathbf{i}$ pasture to cropland conversion. Refer to Table 2 for abbreviations
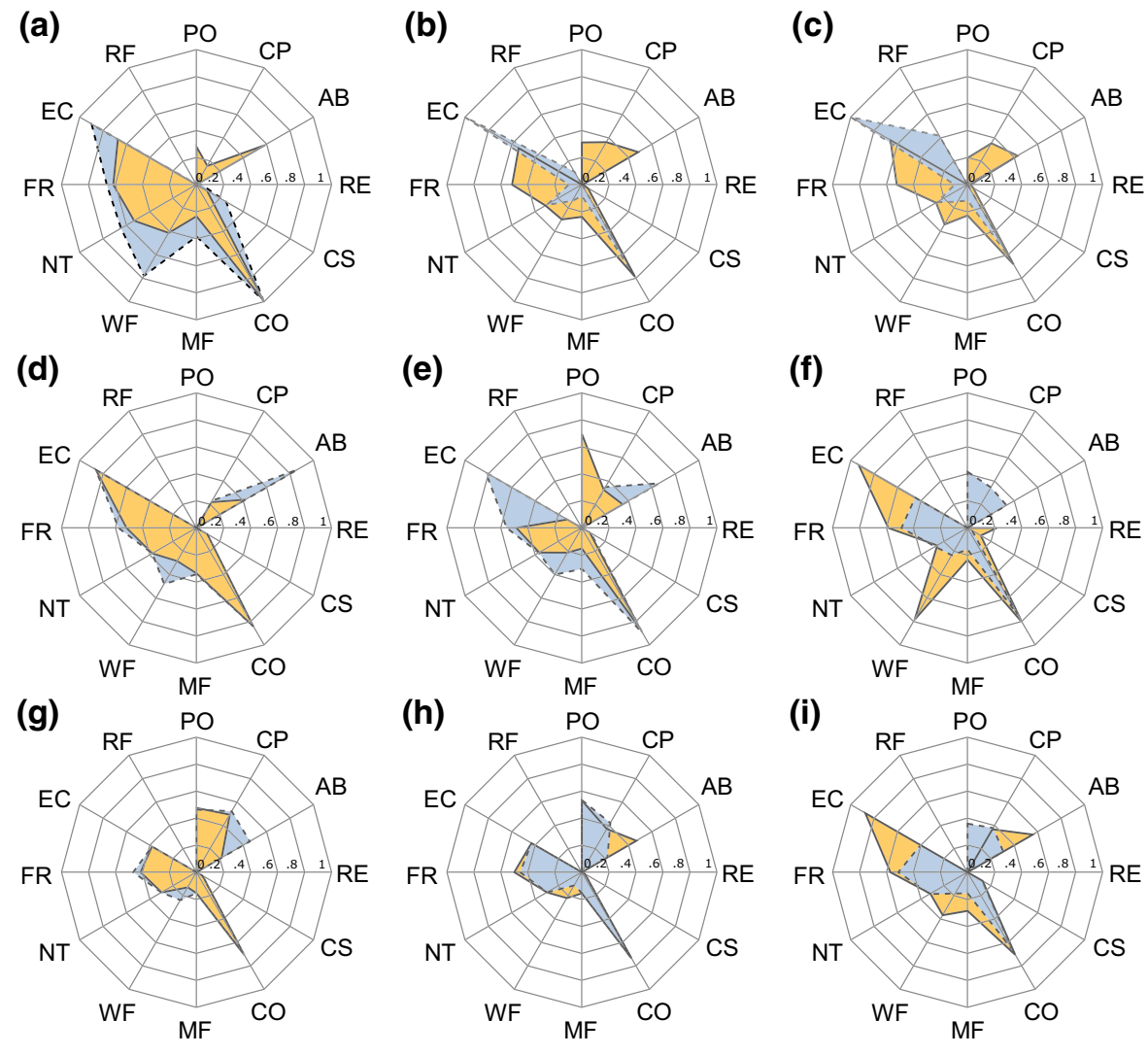

in 2000

in V-B2 (2040) supply is accounted for, diversity does not straightforwardly translate into high levels of multifunctionality. The local context and the composition and configuration of the landscape are important determinants of its functioning that cannot be captured in simplified indicators. When re-designing landscape management, rather than simply targeting high land use diversity or multifunctionality, the functioning of the ecosystems in relation to specific service demands should be accounted for. Similar considerations hold for the design of land use policies to guide land use change. In scenarios, multiple land change trajectories occur over the EU territory at the same time, each having its own impact on multifunctionality in often opposing ways. Rather than prohibiting certain land use changes at large, it is more beneficial to guide and steer land use changes towards those locations where most beneficial impacts are expected. The analyses made in this paper provide a tool to identify such locations and measure the multiple aspects of multifunctionality related to land use change.

\section{Conclusions}

Our study has indicated that in quantifying landscape multifunctionality at EU level, the choice of indicator and scale of analysis can strongly affect the results. There is no single best multifunctionality indicator. Choosing a suitable indicator depends on the research question. It might require multiple indicators to address the different aspects of multifunctionality. We have shown that particularly the scale of analysis affects the results, and thus, interpretation of multifunctionality indicators is dependent of the scale of analysis. Particularly analyses at coarse scales, such as the administrative NUTS2 regions, may lump ES provided by different ecosystems and landscapes occurring within the administrative unit rather than referring to the multifunctionality of single land use units or landscapes.

In the analysis at EU level, but also for different landscape types, we could not find a generally higher multifunctionality at locations providing higher levels 


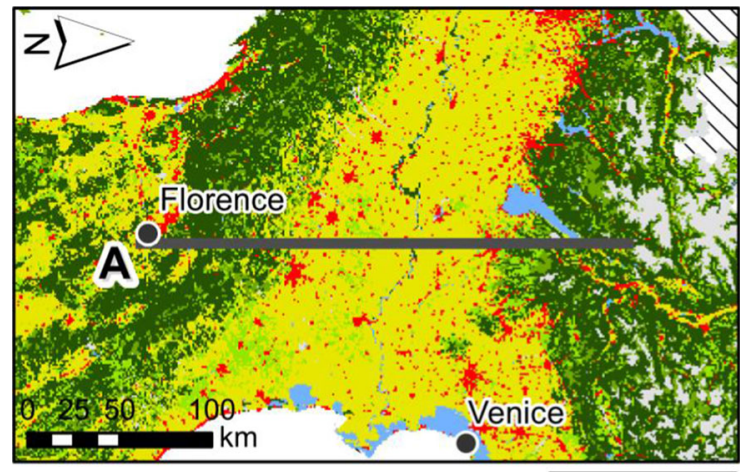

\section{Land use}
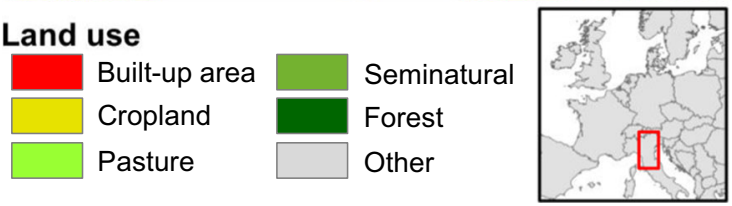

(a)

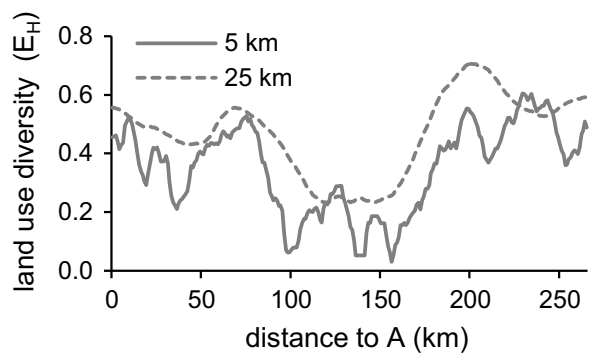

(b)

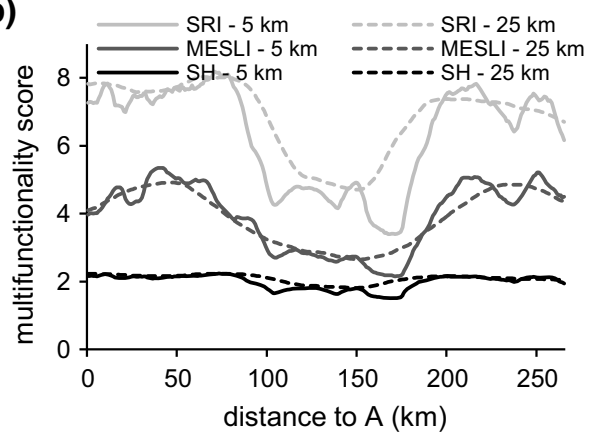

Fig. 8 a Land use diversity and $\mathbf{b}$ multifunctionality according to several multifunctionality indicators at different analysis scales along a transect

of land use diversity. The relationship between multifunctionality and land use diversity is clearly more complex and location dependent. Similar considerations hold for the diverse impacts of modeled land change in the EU on multifunctionality across scales and indicators. Large impacts in locations and regions are cancelled out at higher levels of aggregation due to the different impacts of different land change trajectories and the trade-offs between ES upon land use change. Therefore, rather than focusing on the impact of land use change on aggregated multifunctionality indicators, it is recommended to base land use policy on the location-specific impacts of land use changes on ecosystem services and functions, and societal demand for them.

Acknowledgements The work conducted in this paper was financed by the European Comission-FP7 Projects VOLANTE (No. 265104) and OPERAs (No. 308393).

Open Access This article is distributed under the terms of the Creative Commons Attribution 4.0 International License (http:// creativecommons.org/licenses/by/4.0/), which permits unrestricted use, distribution, and reproduction in any medium, provided you give appropriate credit to the original author(s) and the source, provide a link to the Creative Commons license, and indicate if changes were made.

\section{References}

Allan E, Manning P, Alt F, Binkenstein J, Blaser S, Blüthgen N, Böhm S, Grassein F, Hölzel N, Klaus VH, Kleinebecker T (2015) Land use intensification alters ecosystem multifunctionality via loss of biodiversity and changes to functional composition. Ecol Lett 18:834-843

Altieri M (2000) Multifunctional dimensions of ecologicallybased agriculture in Latin America. Int J Sustain Dev World Ecol 7:62-75

Andersson E, Nykvist B, Malinga R, Jaramillo F, Lindborg R (2015) A social-ecological analysis of ecosystem services in two different farming systems. Ambio 44:102-112

Beese F (1996) Indicators for a concept of mulifunctional forest use. Forstwiss Cent 115:65-79

Bennett EM, Peterson GD, Gordon LJ (2009) Understanding relationships among multiple ecosystem services. Ecol Lett 12:1394-1404

Bradford MA, Wood SA, Bardgett RD, Black HI, Bonkowski M, Eggers T, Grayston SJ, Kandeler E, Manning P, Setälä $\mathrm{H}$, Jones TH (2014) Discontinuity in the responses of ecosystem processes and multifunctionality to altered soil community composition. Proc Natl Acad Sci USA 111:14478-14483

Bright EA, Coleman PR, King AL, Rose AN (2008) LandScan 2007 TM high resolution global population data set. Oak Ridge, TN. http://www.ornl.gov/landscan/. Accessed March 2015

Bullock JM, Aronson J, Newton AC, Pywell RF, Rey-Benayas JM (2011) Restoration of ecosystem services and biodiversity: conflicts and opportunities. Trends Ecol Evol 26:541-549

Burkhard B, Kroll F, Müller F, Windhorst W (2009) Landscapes' capacities to provide ecosystem services-a concept for land-cover based assessments. Landsc Online $15: 1-22$ 
Cardinale BJ, Duffy JE, Gonzalez A, Hooper DU, Perrings C, Venail P, Narwani A, Mace GM, Tilman D, Wardle DA, Kinzig AP (2012) Biodiversity loss and its impact on humanity. Nature 486:59-67

Cerqueira Y, Navarro LM, Maes J, Marta-Pedroso C, Honrado JP, Pereira HM (2015) Ecosystem services: the opportunities of rewilding in Europe. In: Pereira HM, Navarro LM (eds) Rewilding European landscapes. Springer International Publishing, Cham, pp 47-64

Crouzat E, Mouchet M, Turkelboom F, Byczek C, Meersmans J, Berger F, Verkerk PJ, Lavorel S (2015) Assessing bundles of ecosystem services from regional to landscape scale: insights from the French Alps. J Appl Ecol 52:1145-1155

Dobson A, Lodge D, Alder J, Cumming GS, Keymer J, McGlade J, Mooney H, Rusak JA, Sala O, Wolters V, Wall D (2006) Habitat loss, trophic collapse, and the decline of ecosystem services. Ecology 87:1915-1924

Elmhagen B, Eriksson O, Lindborg R (2015) Implications of climate and land-use change for landscape processes, biodiversity, ecosystem services, and governance. Ambio 44:1-5

Fuchs R, Herold M, Verburg PH, Clevers JGPW, Eberle J (2015) Gross changes in reconstructions of historic land cover/use for Europe between 1900 and 2010. Glob Chang Biol 21:299-313

Galler C (2015) Koordinationsbedarf in der Umweltplanung zur Optimierung multifunktionaler Maßnahmeneffekte. In: Karl H (ed) Koordination raumwirksamer Politik. Forschunsgberichte der ARL 4, Hannover, pp 152-173

Gingrich S, Niedertscheider M, Kastner T, Haberl H, Cosor G, Krausmann F, Kuemmerle T, Müller D, Reith-Musel A, Jepsen MR, Vadineanu A (2015) Exploring long-term trends in land use change and aboveground human appropriation of net primary production in nine European countries. Land Use Policy 47:426-438

Goldstein JH, Caldarone G, Duarte TK, Ennaanay D, Hannahs N, Mendoza G, Polasky S, Wolny S, Daily GC (2012) Integrating ecosystem-service tradeoffs into land-use decisions. Proc Natl Acad Sci USA 109:7565-7570

Gustafson EJ, Parker GR (1994) Using an index of habitat patch proximity for landscape design. Landsc Urban Plan 29:117-130

Hansen R, Pauleit S (2014) From multifunctionality to multiple ecosystem services? A conceptual framework for multifunctionality in green infrastructure planning for urban areas. Ambio 43:516-529

Helming K, Tscherning K, König B, Sieber S, Wiggering H, Kuhlman T, Wascher D, Perez-Soba M, Smeets P, Tabbush P, Dilly O, Hüttl R, Bach H (2008) Ex ante impact assessment of land use changes in European regions- the SENSOR approach. In: Helming K, Perez-Soba M, Tabbush P (eds) Sustainability impact assessment of land use changes. Part 1. Springer, Berlin, pp 77-105

Hill M (1973) Diversity and evenness: a unifying notation and its consequences. Ecology 54:427-432

Howe C, Suich H, Vira B, Mace GM (2014) Creating win-wins from trade-offs? Ecosystem services for human well-being: a meta-analysis of ecosystem service trade-offs and synergies in the real world. Glob Environ Chang 28:263-275

Kienast F, Bolliger J, Potschin M, De Groot RS, Verburg PH, Heller I, Wascher D, Haines-Young R (2009) Assessing landscape functions with broad-scale environmental data: insights gained from a prototype development for Europe. Environ Manag 44:1099-1120

Kremen C, Williams NM, Aizen MA, Gemmill-Herren B, LeBuhn G, Minckley R, Packer L, Potts SG, SteffanDewenter I, Vazquez DP, Winfree R (2007) Pollination and other ecosystem services produced by mobile organisms: a conceptual framework for the effects of land-use change. Ecol Lett 10:299-314

Liu J, Hull V, Batistella M, DeFries R, Dietz T, Fu F, Hertel TW, Izaurralde RC, Lambin EF, Li S, Martinelli LA (2013) Framing sustainability in a telecoupled world. Ecol Soc $18: 26$

Mace GM, Norris K, Fitter AH (2012) Biodiversity and ecosystem services: a multilayered relationship. Trends Ecol Evol 27:19-26

Maes J, Barbosa A, Baranzelli C, Zulian G, e Silva FB, Vandecasteele I, Hiederer R, Liquete C, Paracchini ML, Mubareka S, Jacobs-Crisioni C (2014) More green infrastructure is required to maintain ecosystem services under current trends in land-use change in Europe. Landscape Ecol 30:517-534

Maes J, Paracchini ML, Zulian G, Dunbar MB, Alkemade R (2012) Synergies and trade-offs between ecosystem service supply, biodiversity, and habitat conservation status in Europe. Biol Conserv 155:1-12

Mastrangelo M, Weyland F, Villarino S, Barral MP, Nahuelhual L, Laterra P (2014) Concepts and methods for landscape multifunctionality and a unifying framework based on ecosystem services. Landscape Ecol 29:345-358

McGranahan DA (2014) Ecologies of scale: multifunctionality connects conservation and agriculture across fields, farms, and landscapes. Land 3:739-769

Metzger MJ, Schröter D, Leemans R, Cramer W (2008) A spatially explicit and quantitative vulnerability assessment of ecosystem service change in Europe. Reg Environ Chang 8:91-107

Nabuurs GJ, Pussinen A, van Brusselen J, Schelhaas MJ (2007) Future harvesting pressure on European forests. Eur J For Res 126:391-400

Nakicenovic N, Swart R (2000) Special report on emissions scenarios. Cambridge University Press, Cambridge

Otte A, Simmering D, Wolters V (2007) Biodiversity at the landscape level: recent concepts and perspectives for multifunctional land use. Landscape Ecol 22:639-642

Overmars KP, Schulp CJE, Alkemade R, Verburg PH, Temme AJ, Omtzigt N, Schaminée JH (2014) Developing a methodology for a species-based and spatially explicit indicator for biodiversity on agricultural land in the EU. Ecol Indic 37:186-198

Paletto A, Ferretti F, Cantiani P, De Meo I (2012) Multi-functional approach in forest landscape management planning: an application in Southern Italy. For Syst 21:68-80

Pasari JR, Levi T, Zavaleta ES, Tilman D (2013) Several scales of biodiversity affect ecosystem multifunctionality. Proc Natl Acad Sci USA 110:10219-10222

Pérez-Soba M, Elbersen B, Kempen M, Braat L, Staristky I, van der Wijngaart R, Kaphengst T, Andersen E, Germer L, Smith L, Rega C, Paracchini, ML (2015) Agricultural biomass as provisioning ecosystem service: quantification of energy flows. EUR27538 EN. doi:10.2788/679096 
Pielou EC (1966) Shannon's Formula as a measure of specific diversity: its use and misuse. Am Nat 100:463-465

Plieninger T, Bieling C, Ohnesorge B, Schaich H, Schleyer C, Wolff $F$ (2013a) Exploring futures of ecosystem services in cultural landscapes through participatory scenario development in the Swabian Alb, Germany. Ecol Soc 18:39

Plieninger T, Dijks S, Oteros-Rozas E, Bieling C (2013b) Assessing, mapping, and quantifying cultural ecosystem services at community level. Land Use Policy 33:118-129

Queiroz C, Meacham M, Richter K, Norström AV, Andersson E, Norberg J, Peterson G (2015) Mapping bundles of ecosystem services reveals distinct types of multifunctionality within a Swedish landscape. Ambio 44:89-101

Raudsepp-Hearne C, Peterson GD (2016) Scale and ecosystem services: how do observation, management, and analysis shift with scale-lessons from Québec. Ecol Soc 21:16

Raudsepp-Hearne C, Peterson GD, Bennett EM (2010) Ecosystem service bundles for analyzing tradeoffs in diverse landscapes. Proc Natl Acad Sci USA 107: 5242-5247

Rey Benayas J (2007) Abandonment of agricultural land: an overview of drivers and consequences. CAB Rev 2:1-14

Rodríguez-Loinaz G, Alday JG, Onaindia M (2015) Multiple ecosystem services landscape index: a tool for multifunctional landscapes conservation. J Environ Manag 147:152-163

Schindler S, Sebesvari Z, Damm C, Euller K, Mauerhofer V, Schneidergruber A, Biró M, Essl F, Kanka R, Lauwaars SG, Schulz-Zunkel C (2014) Multifunctionality of floodplain landscapes: relating management options to ecosystem services. Landscape Ecol 29:229-244

Schulp CJE, Burkhard B, Maes J, Van Vliet J, Verburg PH (2014a) Uncertainties in ecosystem service maps: a comparison on the European scale. PLoS ONE 9:e109643

Schulp CJE, Nabuurs GJ, Verburg PH (2008) Future carbon sequestration in Europe-effects of land use change. Agric Ecosyst Environ 127:251-264

Schulp CJE, Thuiller W, Verburg PH (2014b) Wild food in Europe: a synthesis of knowledge and data of terrestrial wild food as an ecosystem service. Ecol Econ 105:292-305

Selman P (2009) Planning for landscape multifunctionality. Sustainability 5:45-52

Serna-Chavez HM, Schulp CJE, van Bodegom PM, Bouten W, Verburg PH, Davidson MD (2014) A quantitative framework for assessing spatial flows of ecosystem services. Ecol Indic 39:24-33
Stürck J, Levers C, van der Zanden EH, Schulp CJE, Verkerk PJ, Kuemmerle T, Helming J, Lotze-Campen H, Tabeau A, Popp A, Schrammeijer E (2015) Simulating and visualizing future land change trajectories in Europe. Reg Environ Chang. doi:10.1007/s10113-015-0876-0

Stürck J, Poortinga A, Verburg PH (2014) Mapping ecosystem services: the supply and demand of flood regulation services in Europe. Ecol Indic 38:198-211

Tramer EJ (1969) Bird species diversity: components of Shannon's formula. Ecology 50:927-929

Tucker G, Allen B, Conway M, Dickie I, Hart K, Rayment M, Schulp C, van Teeffelen A (2013) Policy options for an EU no net loss initiative. Report to the European Commission. Institute for European Environmental Policy, London. http://ec.europa.eu/environment/nature/biodiversity/nnl/ pdf/Policy\%20Options.pdf. Accessed July 2015

van Berkel DB, Verburg PH (2011) Sensitising rural policy: assessing spatial variation in rural development options for Europe. Land Use Policy 28:447-459

van der Zanden EH (2016) Agricultural landscapes in Europe: spatial structure, land management an consequences of agricultural abandonment. PhD thesis, Vrije Universiteit Amsterdam, The Netherlands, p 204

van Zanten BT, Verburg PH, Espinosa M, Gomez-y-Paloma S, Galimberti G, Kantelhardt J, Kapfer M, Lefebvre M, Manrique R, Piorr A, Raggi M (2014) European agricultural landscapes, common agricultural policy and ecosystem services: a review. Agron Sustain Dev 34:309-325

Verburg PH, Overmars KP (2009) Combining top-down and bottom-up dynamics in land use modeling: exploring the future of abandoned farmlands in Europe with the DynaCLUE model. Landscape Ecol 24:1167-1181

Verburg PH, Tabeau A, Hatna E (2013) Assessing spatial uncertainties of land allocation using a scenario approach and sensitivity analysis: a study for land use in Europe. J Environ Manag 127:S132-S144

Verkerk PJ, Anttila P, Eggers J, Lindner M, Asikainen A (2011) The realisable potential supply of woody biomass from forests in the European Union. For Ecol Manag 261:2007-2015

Waldhardt R, Bach M, Borresch R, Breuer L, Diekötter T, Frede HG, Gäth S, Ginzler O, Gottschalk T, Julich S, Krumpholz M (2010) Evaluating today's landscape multifunctionality and providing an alternative future: a normative scenario approach. Ecol Soc 15:30 